\title{
Integration of prognostic aerosol-cloud interactions in a chemistry transport model coupled offline to a regional climate model
}

\author{
M. A. Thomas ${ }^{1}$, M. Kahnert ${ }^{1,2}$, C. Andersson ${ }^{1}$, H. Kokkola ${ }^{3}$, U. Hansson ${ }^{1}$, C. Jones ${ }^{1,4}$, J. Langner ${ }^{1}$, and \\ A. Devasthale ${ }^{1}$ \\ ${ }^{1}$ Research Department, Swedish Meteorological and Hydrological Institute, Folkborgsvägen 17, 60176 Norrköping, Sweden \\ ${ }^{2}$ Department of Earth and Space Sciences, Chalmers University of Technology, 41296 Gothenburg, Sweden \\ ${ }^{3}$ Finnish Meteorological Institute, Kuopio, Finland \\ ${ }^{4}$ National Centre for Atmospheric Science, School of Earth and Environment, University of Leeds, LS2 9JT Leeds, UK
}

Correspondence to: M. A. Thomas (manu.thomas@smhi.se)

Received: 25 November 2014 - Published in Geosci. Model Dev. Discuss.: 03 February 2015

Revised: 08 June 2015 - Accepted: 12 June 2015 - Published: 30 June 2015

\begin{abstract}
To reduce uncertainties and hence to obtain a better estimate of aerosol (direct and indirect) radiative forcing, next generation climate models aim for a tighter coupling between chemistry transport models and regional climate models and a better representation of aerosol-cloud interactions. In this study, this coupling is done by first forcing the Rossby Center regional climate model (RCA4) with ERA-Interim lateral boundaries and sea surface temperature (SST) using the standard cloud droplet number concentration (CDNC) formulation (hereafter, referred to as the "standalone RCA4 version" or "CTRL" simulation). In the standalone RCA4 version, CDNCs are constants distinguishing only between land and ocean surface. The meteorology from this simulation is then used to drive the chemistry transport model, Multiple-scale Atmospheric Transport and Chemistry (MATCH), which is coupled online with the aerosol dynamics model, Sectional Aerosol module for Large Scale Applications (SALSA). CDNC fields obtained from MATCHSALSA are then fed back into a new RCA4 simulation. In this new simulation (referred to as "MOD" simulation), all parameters remain the same as in the first run except for the CDNCs provided by MATCH-SALSA. Simulations are carried out with this model setup for the period 2005-2012 over Europe, and the differences in cloud microphysical properties and radiative fluxes as a result of local CDNC changes and possible model responses are analysed.

Our study shows substantial improvements in cloud microphysical properties with the input of the MATCH-SALSA derived 3-D CDNCs compared to the stand-alone RCA4 ver-
\end{abstract}

sion. This model setup improves the spatial, seasonal and vertical distribution of CDNCs with a higher concentration observed over central Europe during boreal summer (JJA) and over eastern Europe and Russia during winter (DJF). Realistic cloud droplet radii (CD radii) values have been simulated with the maxima reaching $13 \mu \mathrm{m}$, whereas in the stand-alone version the values reached only $5 \mu \mathrm{m}$. A substantial improvement in the distribution of the cloud liquid-water paths (CLWP) was observed when compared to the satellite retrievals from the Moderate Resolution Imaging Spectroradiometer (MODIS) for the boreal summer months. The median and standard deviation values from the "MOD" simulation are closer to observations than those obtained using the stand-alone RCA4 version. These changes resulted in a significant decrease in the total annual mean net fluxes at the top of the atmosphere (TOA) by $-5 \mathrm{~W} \mathrm{~m}^{-2}$ over the domain selected in the study. The TOA net fluxes from the "MOD" simulation show a better agreement with the retrievals from the Clouds and the Earth's Radiant Energy System (CERES) instrument. The aerosol indirect effects are estimated in the "MOD" simulation in comparison to the pre-industrial aerosol emissions (1900). Our simulations estimated the domain averaged annual mean total radiative forcing of $-0.64 \mathrm{~W} \mathrm{~m}^{-2}$ with a larger contribution from the first indirect aerosol effect $\left(-0.57 \mathrm{~W} \mathrm{~m}^{-2}\right)$ than from the second indirect aerosol effect $\left(-0.14 \mathrm{~W} \mathrm{~m}^{-2}\right)$. 


\section{Introduction}

The scientific understanding of the climate effects of the different aerosol species as well as their representation in models and their physical and chemical transformation under different meteorological conditions is still low (Boucher et al., 2013). Aerosols have a direct radiative effect by scattering and absorbing shortwave and long-wave radiation, thereby changing the reflectivity, transmissivity and absorptivity of the atmosphere. They can further act as cloud condensation nuclei (CCN), thereby influencing the microphysical properties of clouds. This, in turn, can impact the optical properties and lifetimes of clouds, thus indirectly affecting the radiative properties of the atmosphere (Penner et al., 2004). Apart from ambient conditions, the ability of the aerosols to act as $\mathrm{CCN}$ depends on the size distribution (Dusek et al., 2006) and, for particles in the size range between 40 and $200 \mathrm{~nm}$, on the chemical composition and mixing state (McFiggans et al., 2006).

The direct effect of aerosols and, even more so, their indirect impact on radiative forcing have been identified as the largest sources of uncertainty in quantifying the radiative energy budget and its impact on climate system (Forster et al., 2007). An accurate estimate of these effects requires the coupling of atmospheric chemistry/aerosols to global circulation models (GCMs); however, due to their coarse resolution, their accuracy reduces when one starts to zoom into regional scales. Hence, the recent generation of models uses the regional climate models at a higher horizontal and vertical resolution instead of GCMs, for example, WRFChem (Grell et al., 2005), ENVIRO-HIRLAM (Baklanov et al., 2008), RegCM3-CAMx (Huszar et al., 2012; Qian and Giorgi, 1999; Qian et al., 2001). Recently, Baklanov et al. (2014) summarized the status of the online/offline European coupled meteorology and chemistry transport models with varying degrees of complexity in the representation of dynamical and physical processes, aerosol-cloud-climate interactions, radiation schemes, etc. The main conclusion was that an online integrated modelling approach is the future and can be adapted to several modelling communities such as climate modelling and air-quality-related studies depending on the objective of the study (Baklanov et al., 2014, and the references therein). The study also showed that for climate modelling, the inclusion of feedback processes is the most important and significant improvements were noticeable in climate-chemistry/aerosols interactions. Whether the coupling need to be online or offline depends on the specific study. For example, Folberth et al. (2011) showed that in long-lived greenhouse gas forcing experiments, the online approach did not give significant improvements, whereas for short-lived climate forcers, aerosols in particular, the online approach is very beneficial. The aerosol-cloud interactions, in particular, are either implicity or explicitly included in all online models. Schemes (e.g. Abdul-Razzak and Ghan, 2002) that explicitly resolve the activation of $\mathrm{CCN}$ to cloud droplets are currently included only in a handful of online coupled models (ENVIRO-HIRLAM, WRF-Chem, etc). Instead, the droplet number concentrations are derived empirically and are used in the parameterization of droplet radii and autoconversion processes.

Here, we attempt a similar approach by adapting the Rossby Center regional climate model (RCA4) for the offline ingestion of cloud droplet number concentrations (CDNCs) from the cloud activation module embedded in the chemistry transport model, Multiple-scale Atmospheric Transport and Chemistry (MATCH), that is coupled online to the aerosol dynamics model, Sectional Aerosol module for Large Scale Applications (SALSA). Such a setup is useful in many ways:

1. A more detailed description of the emissions, transport, particle growth, deposition and aerosol processes can be included so as to obtain an accurate evaluation of aerosol radiative effects on a higher spatial resolution compared to global models (Colarco et al., 2010).

2. It is possible to assess the level of detail that is required to describe the effects on a regional scale.

3. It can be used to assess the effects of future climate change on air quality.

In this paper, we present the results from a full fledged working version of the coupling between a chemistry transport model (CTM) with a detailed aerosol dynamics model and a regional climate model. The coupling between these two model systems is offline and is done through CDNCs calculated by the CTM. The drawback of offline coupling is that there is no feedback on the simulation of chemistry and aerosols from changes in meteorology due to altered $\mathrm{CDNC}$ /radiation and no coupling to sea surface temperature (SST). In the following subsections, we introduce the models used in this study, their coupling and the improvements made in the cloud microphysical properties and radiative forcing.

\section{Description of the models and experimental setups}

\subsection{Description of the models}

The schematic of the model coupling is shown in Fig. 1. In this study, we use the Multiple-scale Atmospheric Transport and Chemistry (MATCH) model (Robertson et al., 1999; Andersson et al., 2007) which is an Eulerian CTM that accounts for transport, chemical transformation and deposition of chemical tracers in the atmosphere based on EMEP (European Monitoring and Evaluation Programme) emissions (http://www.ceip.at). The MATCH model is online coupled to the aerosol dynamics model, SALSA (Kokkola et al., 2008) that takes into account physical processes such as nucleation of particles, growth of particles by condensation and coagulation and computes the size distribution, number concentration and chemical composition of the aerosol species. 


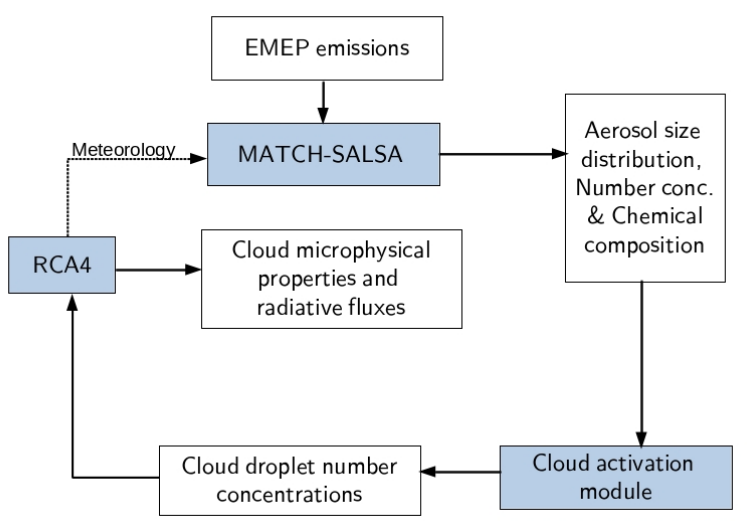

Figure 1. Schematic showing the different model components and their couplings.

A sectional representation of the aerosol size distribution is considered and has three main size regimes (a: $3-50 \mathrm{~nm}, \mathrm{~b}$ : $50-700 \mathrm{~nm}$ and $\mathrm{c}:>700 \mathrm{~nm}$ ) and each regime is again subdivided into smaller bins and into soluble and insoluble bins adding up to a total of 20 bins. A schematic of the sectional size distribution and the aerosol species considered in each bin is shown in Fig. 2. Anthropogenic emissions such as primary particulate matter (PM), $\mathrm{NO}_{x}$, NMVOC (Nonmethane volatile organic compounds), $\mathrm{SO}_{x}, \mathrm{NH}_{3}$ and carbon monoxide, volcanic and DMS (Dimethyl sulfide) emissions are taken from the EMEP expert emissions inventory for the year 2003. The aerosol and gaseous concentrations at the lateral and top model boundaries are set as described in Andersson et al. (2007). The boundary concentrations are based on both observations at background locations and large-scale model calculations and are prescribed as monthly or seasonally varying fields. However, the boundary concentrations of organic matter $(\mathrm{OM})$ are set to the seasonally varying mass size distributions and totals of marine $\mathrm{OM}$ as described in O'Dowd et al. (2004). The aerosol number concentrations are also introduced at the southern, western and northern lateral boundaries. These values are prescribed at the first model level and interpolated linearly to the top and eastern boundaries where the concentrations are set to zero. Primary PM is divided into EC (elemental carbon), OC (organic carbon) and other emissions. This division of the primary PM is based on the TNO-MACC (TNO-Monitoring Atmospheric Composition and Climate) emissions of EC and OC (Kuenen et al., 2011; Pouliot et al., 2012; see also the MACC project web page http://www.gmes-atmosphere.eu/). The emissions were given as annual totals. Seasonal, weekday and diurnal variations of the emissions are sector specific and based on results from the GENEMIS (Generation and Evaluation of Emission Data) project (http://genemis.ier.uni-stuttgart.de/; Friedrich and Reis, 2004). The vertical distribution is also sector specific and based on the vertical distribution used by the EMEP

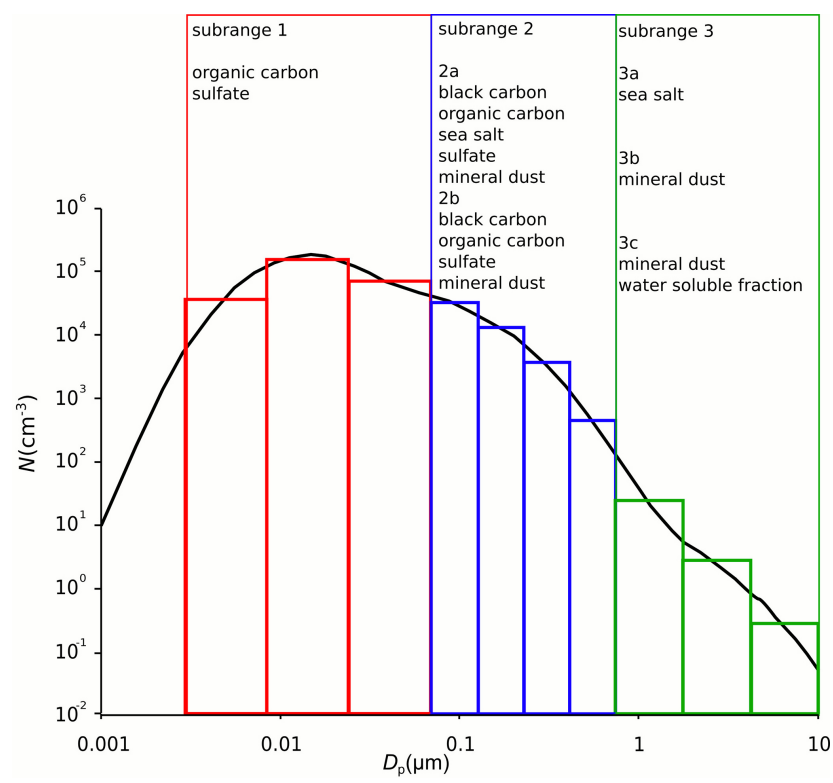

Figure 2. Schematic of sectional distribution of aerosol size bins and the chemical components in the bins (taken from Kokkola et al., 2008).

model. The particle emissions of EC and OC are distributed over different particle sizes according to sector resolved mass size distributions described by Visschedijk et al. (2009); see Andersson et al. (2015) for more details on how the emissions are distributed. Particulate nitrogen is described outside SALSA, i.e. ammonium salts are not taken into account in the modelling of the aerosol microphysical processes. The lack of ammonium nitrate condensation in the aerosol microphysics could cause underestimation of CDNC. Currently there are no parameterizations available that take into account co-condensation of ammonia and nitric acid. Isoprene emissions are modelled online depending on the meteorology based on the methodology by Simpson et al. (1995). The terpene emissions ( $\alpha$-pinene) are taken from the modelled fields by the EMEP model. Sea salt is parameterized following the scheme of Foltescu et al. (2005) but modified for varying particle sizes. This means that Mårtensson et al. (2003) is used if the particle diameter is $\leq 1 \mu \mathrm{m}$ otherwise Monahan et al. (1986) is used.

The coupling of MATCH with SALSA and the evaluation of this model setup is described in detail in Andersson et al. (2015). A cloud activation model that computes 3-D CDNCs based on the prognostic parameterization scheme of Abdul-Razzak and Ghan (2002) specifically designed for aerosol representation with sectional bins is embedded in the MATCH-SALSA model. In addition to the updraft velocity and supersaturation of the air parcel, this scheme simulates the efficiency of an aerosol particle to be converted to a cloud droplet depending on the number concentration and chemical composition of the particles. The updraft velocity is computed as the sum of the grid mean vertical veloc- 
ity and turbulent kinetic energy (TKE) for stratiform clouds (Lohmann et al., 1999) derived from the RCA4 simulation. These CDNCs are then offline coupled to a regional climate model, RCA4 (Samuelsson et al., 2011), that provides us information on cloud microphysical properties such as cloud droplet radii, cloud liquid-water path as well as radiative fluxes. In the stand-alone version of RCA4, the total number of cloud particles were set to constant values over the whole domain based on whether the surface is oceanic $\left(150 \mathrm{~cm}^{-3}\right)$ or land $\left(400 \mathrm{~cm}^{-3}\right)$ and scaled vertically. These constant values were further used in calculation of effective radius of cloud droplets and in the autoconversion process (conversion of cloud droplet to rain). In this work, the 3-D CDNC fields obtained from the cloud activation model in MATCHSALSA are now used in the RCA4 simulation.

\subsection{Experimental setup - 1}

For the simulations, RCA4 is run with 6-hourly ERA-Interim meteorology on lateral boundaries and sea surface temperature and the 3-hourly RCA4 meteorological fields along with fields necessary to compute the updraft velocity are used to drive the MATCH-SALSA-cloud activation model. The aerosol properties are used in the cloud activation model to derive the 6-hourly CDNCs which are then employed to rerun RCA4 with dynamic rather than prescribed CDNCs to obtain cloud microphysical properties and radiative effects. The CDNC data are interpolated at every time step in the RCA4 model. Simulations were carried out with this model setup at $44 \mathrm{~km} \times 44 \mathrm{~km}$ spatial resolution for the European domain and 24 levels in the vertical (up to $200 \mathrm{hPa}$ ) for an 8-year period (2005-2012). Here, we look into the improvements in the cloud microphysical properties and radiative fluxes with the incorporation of dynamic CDNCs where only local land surface fluxes can respond to these changes, hereby referred to as the MOD simulation. These results are compared with the control simulation, hereby referred to as the CTRL simulation in which the stand-alone version of RCA4 is used.

\subsection{Experimental setup - 2}

To evaluate the indirect aerosol effects due to the present-day (PD) anthropogenic aerosols, the pre-industrial (PI) emissions required for this simulation were taken from those developed for the ECLAIRE project (effects of climate change on air pollution impacts and response strategies) for the year 1900 (http://www.eclaire-fp7.eu). The PI anthropogenic precursor emissions were provided for $\mathrm{CO}, \mathrm{NH}_{3}, \mathrm{NO}_{x}, \mathrm{SO}_{x}$ and volatile organic compound (VOC). Other emissions such as biogenic emissions, DMS and volcanic are kept the same as in the original model setup. The particulate organic matter emissions are reduced to $14 \%$ of the current emission levels in the pre-industrial setup based on the study by Carslaw et al. (2013). Simulations were carried out at the same spatial resolution as in the previous setup and for the same European domain and for the same meteorology from 2005 to 2012 . Here, we address the changes in cloud properties with respect to the emissions from the PI period without the climate feedbacks and we analyse the total radiative forcing. To evaluate the individual contribution from the first and second indirect aerosol effects to the total radiative forcings, two additional simulations each (for PI and PD climate) were carried out. We turn off the individual indirect aerosol effects (IAEs) by prescribing the constant CDNC values for the calculation of one IAE at a time; for example, to evaluate the sole contribution from the first IAE, 3-D CDNC fields are used in the computation of cloud droplet (CD) radius to assess the changes in cloud albedo (first IAE) and constant CDNC values are used in the scheme for the autoconversion process (second IAEs) and vice versa.

\section{Model evaluation and results}

\subsection{Aerosol number concentrations}

Figure 3 shows the spatial distribution of the seasonal mean accumulation mode aerosol number concentrations from MATCH-SALSA model simulations driven by RCA4 meteorology. The main contribution to accumulation mode particles are from $\mathrm{SO}_{4}^{2-}, \mathrm{EC}, \mathrm{OC}$, sea salt and mineral dust. In the figure, emphasis is given to accumulation mode particles as they can act as $\mathrm{CCN}$ and, depending on the water availability and updraft velocity, be efficiently converted into cloud droplets. A clear seasonality is noticeable with the highest concentrations during the summer months and lowest during the winter months. Concentrations reach as high as $600 \mathrm{~cm}^{-3}$ over the southern European subcontinent during summer. This may be partly due to relatively large emissions of primary fine particles and gaseous $\mathrm{SO}_{x}$ (Spracklen et al., 2010; Yu and Luo, 2009), and partly due to less precipitation in southern Europe compared to the rest of Europe resulting in longer residence times of these particles in the atmosphere (Andersson et al., 2013, 2015).

\subsection{Cloud droplet number concentrations}

The seasonal mean in-cloud averaged CDNCs for the European domain is presented in Fig. 4. During boreal summer, CDNCs are extremely high, reaching as high as $225 \mathrm{~cm}^{-3}$ over central Europe mainly because of summer time vertical mixing, high probability of liquid clouds and is also consistent with high aerosol number concentrations simulated during this time. The land-sea contrast is more prominent during the summer months compared to the other seasons. A closer comparison with Fig. 3 reveals that regions of high CDNCs correspond mostly with regions of high accumulation mode aerosol particles. However, in some regions, this correlation is not very noticeable, especially over the Mediterranean in summer. This may be due to subsidence and lack of clouds 

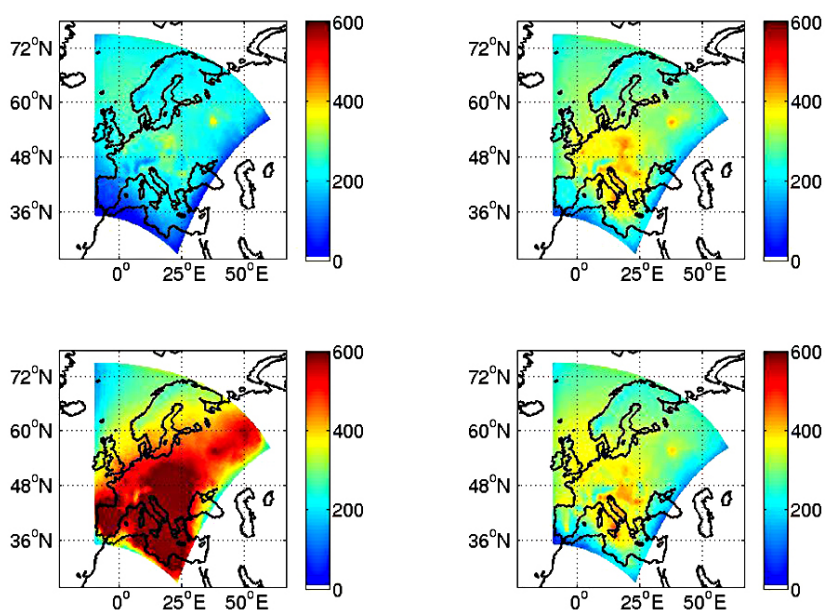

Figure 3. Averaged aerosol number concentrations in the accumulation mode $\left(\mathrm{cm}^{-3}\right)$.

in these regions. Residential biomass burning is more prominent in late autumn-winter-early spring months over eastern Europe and Russia. Whereas, biogenic VOC emissions are higher in these regions during the summer season (Yttri et al., 2009, 2014). This is reflected in the higher CDNCs over these regions during these seasons.

Storelvmo et al. (2009) showed that differences in the cloud droplet activation would account for about $65 \%$ of the total spread in shortwave forcing. So, it is important to see if this model setup reproduces the spatial distribution of CDNCs realistically. The high droplet concentrations simulated over land compared to oceans agrees well with the previous studies of Barahona et al. (2011) and Moore et al. (2013). Zeng et al. (2014) analysed the CDNCs from the Moderate Resolution Imaging Spectroradiometer (MODIS) and CloudAerosol Lidar with Orthogonal Polarization (CALIOP) sensors and it is evident that the droplet concentrations over the European subcontinent would be on an average between 150 and $200 \mathrm{~cm}^{-3}$, and over oceans the concentrations are as low as $100 \mathrm{~cm}^{-3}$. This agrees well with our simulations.

To understand the vertical distribution of CDNCs, we select the following four regions as in Fig. 5 - R1: Mediterranean R2: eastern Europe R3: central Europe and R4: northern Atlantic. Figure 6 shows the joint histograms of CDNC and height (in $\mathrm{km}$ ) over the four selected regions for winter (DJF) and summer (JJA) months. The colour scale shows the normalized frequency and the deeper shade means there is a high probability for the occurrence of those values. It can be seen that the majority of the CDNC values are less than $500 \mathrm{~cm}^{-3}$, but occasionally values also reach as high as $800 \mathrm{~cm}^{-3}$ irrespective of season and region. The figures also show an interesting seasonality of the PDFs (probability distribution functions) of CDNC. For example over the Mediterranean (R1) two peaks can be observed in summer, one around $3 \mathrm{~km}$ and another in the boundary layer; how-
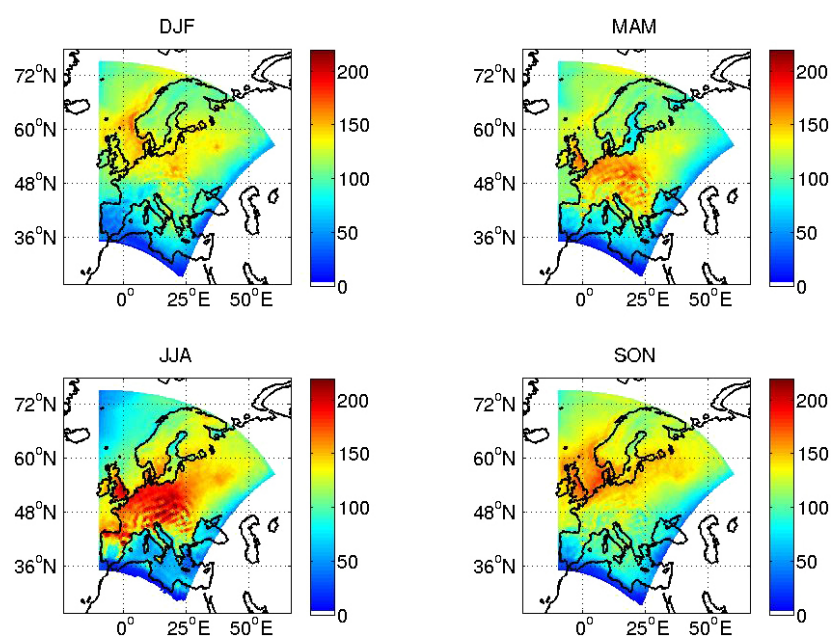

Figure 4. Seasonal mean in-cloud averaged cloud droplet number concentrations $\left(\mathrm{cm}^{-3}\right)$.

ever, in winter, only one peak is present and is located below $2 \mathrm{~km}$. This is mainly due to the stronger vertical mixing of aerosols together with increased buoyancy and convection in summer. It is well known that the frequency of occurrence of very low level water clouds is high over this region during summer, while, in winter, the baroclinic disturbances lead to northward transport of winter storms over this region. Over eastern Europe (R2) and central Europe (R3), the height at which maxima of CDNCs occur is around $1.5 \mathrm{~km}$ in summer, whereas during winter, the maxima is in the boundary layer. The droplet concentrations can vary widely over eastern Europe compared to over central Europe where the concentrations are mostly towards the higher side irrespective of the seasons. The opposite is observed over the northern Atlantic (R4) with a maxima of CDNCs simulated at around $1.5 \mathrm{~km}$ in winter and in the boundary layer in summer. This can be attributed to the long-range transport of pollutants from across the Atlantic observed during the winter months (HTAP, 2010).

\subsection{Cloud droplet radii}

As mentioned in Sect. 2, both the CTRL and MOD simulations follow the same parameterization scheme of Wyser et al. (1999) in the radiation and are formulated in Eq. (1). The effective radius for spherical droplets is estimated as

$r_{\mathrm{e}, \mathrm{water}}=\frac{3 \mathrm{CC}}{4 \pi \rho_{\mathrm{l}} k N}$,

where $\mathrm{CC}$ is the cloud condensate content in $\mathrm{kg} \mathrm{m}^{-3}, \rho_{1}$ is the density of liquid water, $N$ is the number concentration of cloud droplets in $\mathrm{m}^{-3}$ and $k$ is a constant depending on marine or continental clouds. In the CTRL simulation, $N$ was assigned 150 and $400 \mathrm{~cm}^{-3}$ depending on the underlying sur- 


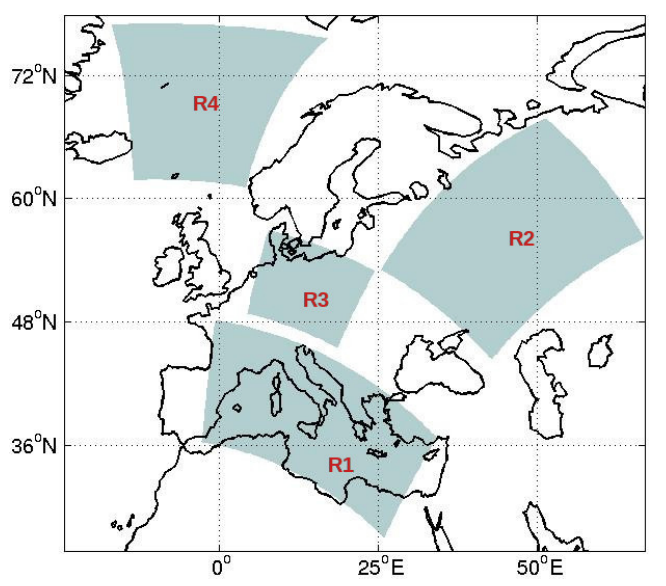

Figure 5. Schematic of the four regions selected for this study. R1 - Mediterranean; R2 - eastern Europe; R3 - central Europe; R4 northern Atlantic.
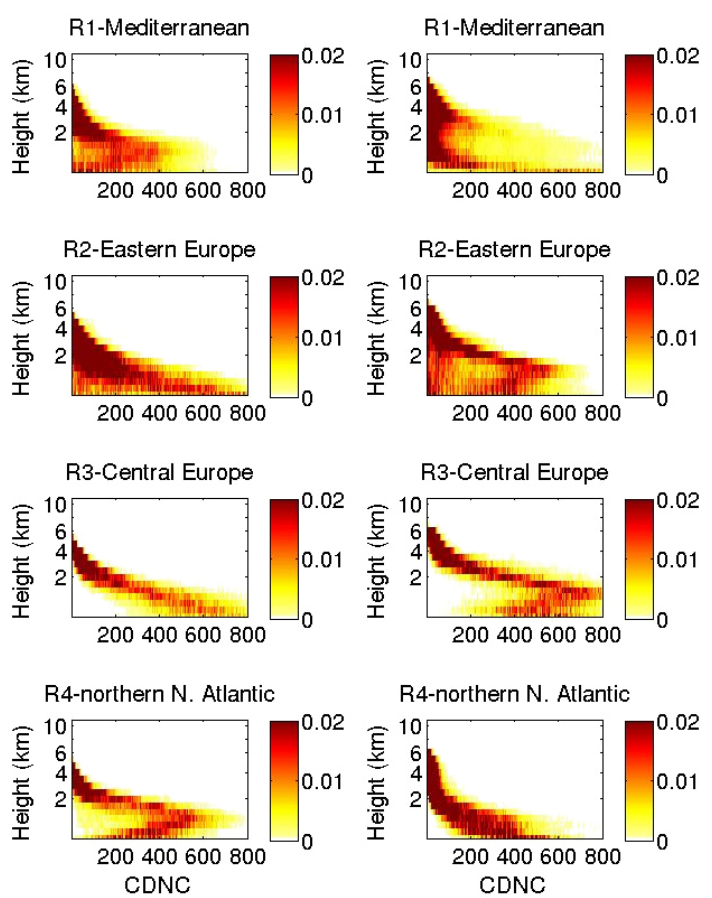

Figure 6. Seasonality in the vertical distributions of CDNC $\left(\mathrm{cm}^{-3}\right)$ shown as joint histograms averaged over winter averaged (DJF) months (first column) and summer averaged (JJA) months (second column) for the selected four regions. The colour scale indicates the normalized frequency.

face; however, in the MOD simulation dynamic CDNCs are used.

The winter and summer mean cloud droplet radii in liquid water clouds for the MOD simulation (top row) and the CTRL simulation (second row) is discussed in Fig. 7. At first glance, apart from the spatial differences, one notices the strong disparity in the range of the radii values. In the MOD
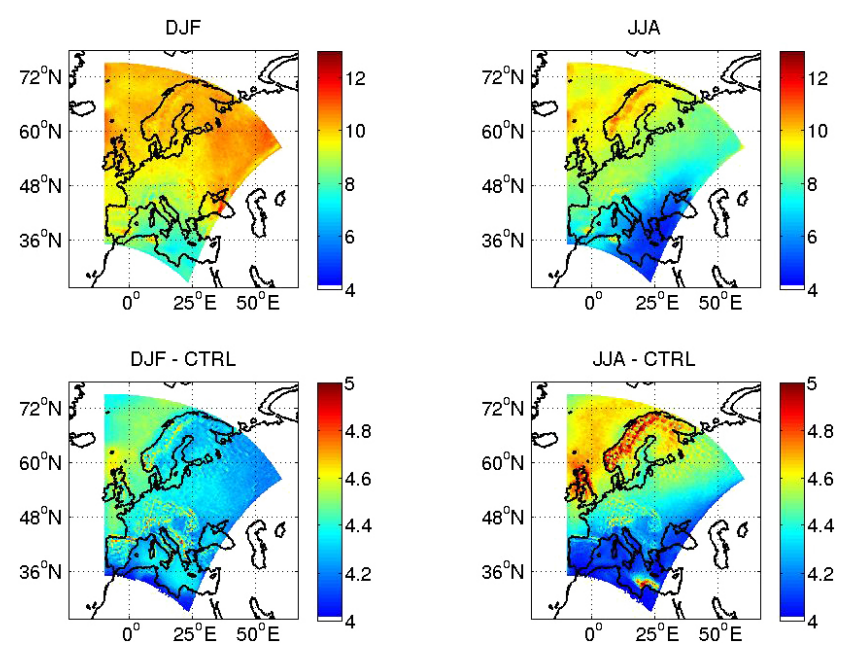

Figure 7. Seasonal mean $\mathrm{CD}$ radii $(\mu \mathrm{m})$ averaged over the entire water cloud for DJF mean and JJA mean in the MOD simulations (top row) and CTRL simulation (second row). Note the difference in scale.

simulation, $\mathrm{CD}$ radii reach as high as $13 \mu \mathrm{m}$, whereas in the CTRL simulation, the maxima observed is $5 \mu \mathrm{m}$. It can be seen that the radii of the droplets are much lower in the summer months compared to the winter months basically due to the increased pollution during summer resulting in smaller droplets.

In Fig. 8, the joint histograms of $\mathrm{CD}$ radii and height during the summer over the Mediterranean and eastern Europe in MOD simulation are shown. The corresponding pattern in the CTRL simulation is shown as the solid line. It can be seen that the CTRL simulation does not exhibit any variability. However, the MOD simulation shows a distinct variability in height and range. It can be seen that over the Mediterranean and over Eastern Europe, a wide range of droplet radii can be observed from as low as 5 up to $16 \mu \mathrm{m}$ and the larger droplets are present at around $2.0-4.0 \mathrm{~km}$. However, there is a higher probability of observing larger droplets over eastern Europe compared to the Mediterranean.

The critical droplet radius at which large-scale precipitation occurs is set to $10 \mu \mathrm{m}$ in the microphysics scheme. This would mean that with these low $\mathrm{CD}$ radii values obtained in the stand-alone RCA4 model, precipitation would be absent. It is important to note that the plotted CD radii values are derived from the model radiation scheme (i.e. this is the radiatively active $\mathrm{CD}$ radii). For more details, refer Appendix A.

\subsection{Cloud liquid-water path}

Figure 9 refers to the percentage change in column integrated cloud water (cloud liquid-water path - CLWP) in the MOD simulations compared to CTRL simulations averaged over the winter (DJF) and summer (JJA) months. Positive values mean that the CLWP increased in the MOD simulations com- 

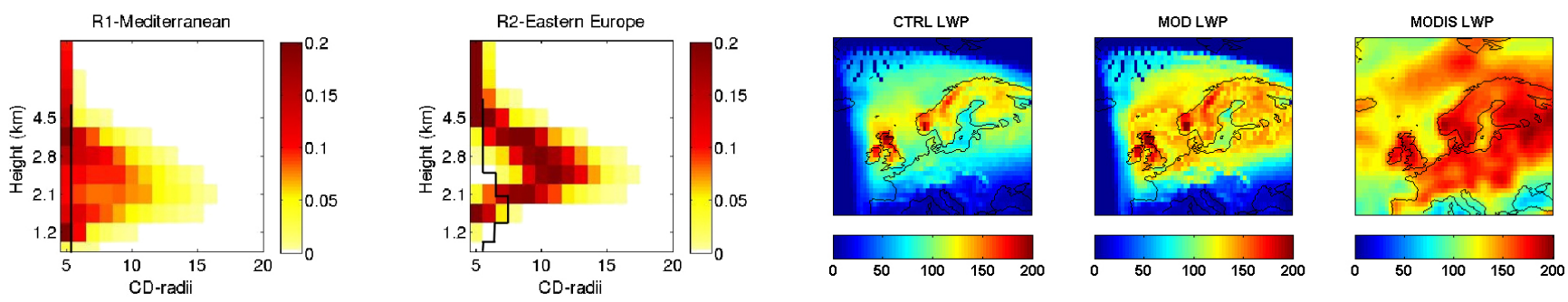

Figure 8. Joint histograms of CD radii $(\mu \mathrm{m})$ vs height averaged over JJA months in MOD simulation and the solid line shows the same in CTRL simulation. The colour scale shows the normalized frequency.
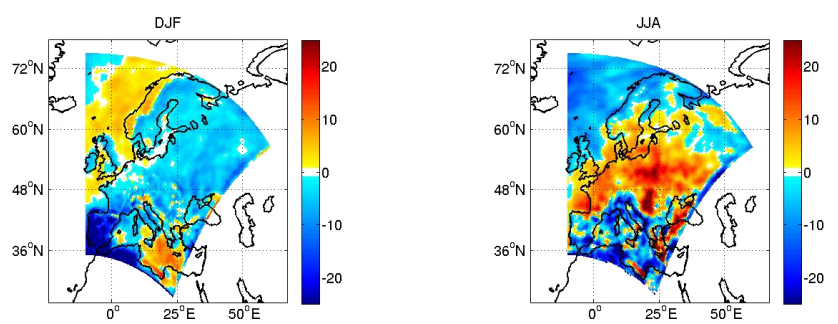

Figure 9. The difference in the vertically integrated cloud water in the MOD simulation compared to the CTRL simulation expressed as a percentage over the winter (DJF) and summer (JJA) months.

pared to the CTRL and vice versa. It can be seen that during the winter months, there is a significant decrease (up to $25 \%$ ) in the vertically integrated cloud liquid water over land and a slight increase over the water bodies when the 3-D CDNCs are used. However, during the summer months, the pattern is reversed with a noticeable increase in the CLWP over most of the European subcontinent. The decrease in the CLWP with increase in CD radii is consistent and may be partly attributed to precipitation removal. In the model, the critical droplet radius at which autoconversion becomes efficient is set to $10 \mu \mathrm{m}$. When the $\mathrm{CD}$ effective radius exceeds this critical droplet radius, precipitation occurs. However, over land during summer, an increase in the CLWP is observed and can be partly due to the fact that the increase in CD radius is not sufficient to trigger precipitation.

We evaluated model simulated cloud liquid-water path estimates using satellite sensor retrievals. We selected the liquid water path (LWP) for evaluation as it is tightly connected not only to other microphysical properties of clouds but also to the first and second indirect aerosol effects, which are the main application focus of the coupling attempted here. We used a decade-long data record (2003-2012) from the MODIS sensor flying onboard NASA's Aqua satellite since 2002 (Platnick et al., 2003; Hubanks et al., 2008). The monthly level 3 data from the collection 5 are analysed over the study area for the boreal summer months of JJA (June, July and August), when liquid clouds are most prevalent and the quality of satellite retrievals is also best. The comparison

Figure 10. Spatial comparison of the simulated cloud liquidwater path $\left(\mathrm{g} \mathrm{m}^{-2}\right)$ (CTRL and MOD) with observations from the MODIS sensor onboard the Aqua satellite for the JJA months.

is shown as spatial distributions in Fig. 10 and as probability density functions of the LWP in Fig. 11 as they cover the whole range of LWP values. We observe substantial improvement in the distribution of LWPs in the MOD simulation compared to the CTRL-simulation. The inclusion of the chemistry-aerosol-cloud microphysical link leads to a more realistic distribution of LWPs that is closer to the observations. At the lower end of the distribution, the model simulates more optically thin liquid water clouds compared to the observations, more predominantly over southern Europe as can be seen in Fig. 10. But the LWP of optically thick clouds, which are most abundant and play a key role in the radiation budget over the study area, shows substantial improvements in the MOD simulation.

\subsection{Total radiative fluxes at the top of the atmosphere}

The difference in the annual mean total net fluxes at the top of the atmosphere (TOA) due to these changes in the cloud microphysical properties is shown in Fig. 12. A significant change is seen over most of the domain with decreases up to $-5 \mathrm{~W} \mathrm{~m}^{-2}$ when the CDNC values are assigned fixed numbers depending on the underlying surface.

To evaluate the TOA radiative fluxes, we used a decadelong data for comparison from the Clouds and the Earth's Radiant Energy System (CERES) sensor that is flying onboard Aqua satellite as well (Wielicki et al., 1996) (More information is available at http://ceres.larc.nasa.gov/documents/DQ summaries/CERES_EBAF_Ed2.8_DQS.pdf). The level 3 Energy Balanced and Filled estimates of all-sky net top of the atmosphere (EBAF-TOA, Edition 2.8) fluxes are analysed for comparison with MOD and CTRL simulations and shown in Fig. 13. The distribution of fluxes in the MOD simulation is closer to the CERES observations compared to CTRL simulation.

\section{Aerosol radiative forcing at the TOA}

In this section, we evaluate the effect of changing cloud albedo and cloud lifetime due to the PD anthropogenic aerosols which is widely known as the first indirect aerosol effect (Twomey, 1959) and the second indirect aerosol effect 


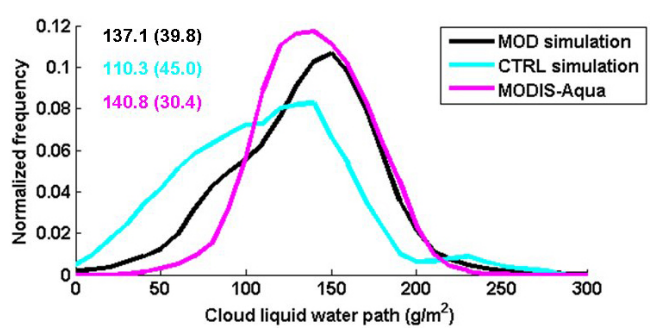

Figure 11. Comparison of cloud liquid-water path $\left(\mathrm{g} \mathrm{m}^{-2}\right)$ with observations from the MODIS sensor onboard the Aqua satellite. The histograms are computed over the entire study area and for the JJA months. The median and standard deviation (in brackets) values are shown for all cases.

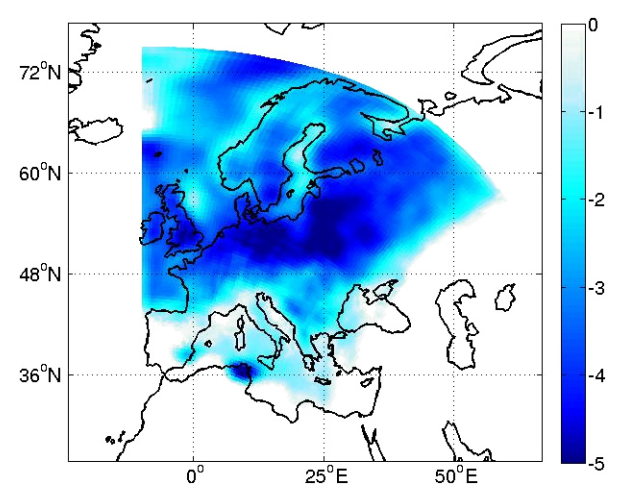

Figure 12. Difference in the annual mean total net fluxes $\left(\mathrm{W} \mathrm{m}^{-2}\right)$ at the TOA in the (MOD-CTRL) case.

(Albrecht, 1989), respectively. In a review paper, Lohmann and Feichter (2005) summarized the aerosol radiative effects into positive and negative perturbations to the radiation budget. Both the indirect aerosol effects tend to cool the Earth system by increasing the cloud optical depth and cloud cover, thereby resulting in the reduction of net radiation reaching the TOA and surface.

The local radiative forcing associated with these IAE are in most cases estimated as the difference between the perturbed and unperturbed radiative fluxes. The perturbed case is the current climate scenario and in the unperturbed case, the fluxes are calculated based on a pre-industrial or pristine scenario with meteorology and SST remaining the same in the both cases. In this study, for the unperturbed case (PI), we use the pre-industrial emissions from 1900s as explained in Sect. 2.3. The PD perturbed case climate scenario is using the MOD simulation setup. In the following paragraphs, we analyse the changes in the CDNC and CLWP in the PD-PI differences and the TOA aerosol radiative forcing over Europe which arises mainly from the response of the land surface without other climate feedbacks. Figures 14,15 and 16 show the annual mean difference in aerosol number concentrations, CDNC and CLWP, respectively, with respect to the PI simulation expressed as a percentage.

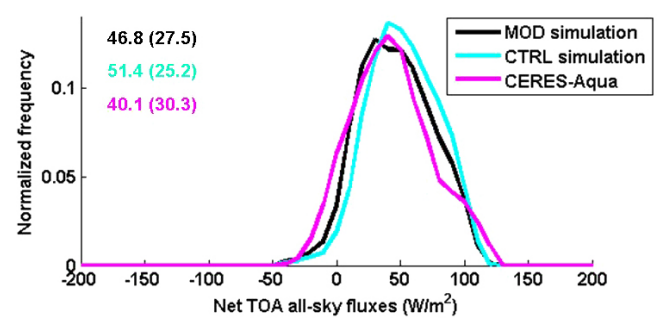

Figure 13. Comparison of total TOA fluxes $\left(\mathrm{W} \mathrm{m}^{-2}\right)$ with observations from the CERES sensor onboard the Aqua satellite. The histograms are computed over the entire study area and for the JJA months. The median and standard deviation (in brackets) values are shown for all cases.

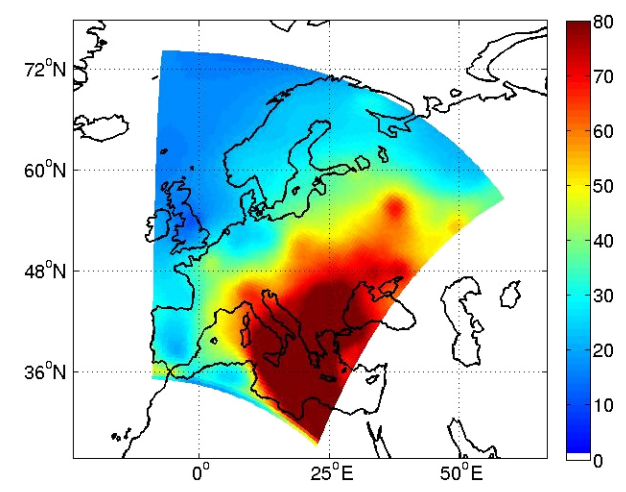

Figure 14. Difference in the annual mean aerosol number concentrations for the (PD-PI) simulation expressed as a percentage.

It can be seen that there is an approximately $50-80 \%$ increase in the aerosol number concentrations with respect to PI era over the southern and eastern European subcontinent and around 10-30\% over the rest of Europe and over the oceans. The steep increase in the aerosol concentrations may be attributed to the increase in anthropogenic pollutant precursor emissions in these countries in the PD. These differences seen in the spatial distribution are reflected as an increase of almost up to $70 \%$ in CDNCs and, correspondingly, an increase of up to $10 \%$ in the CLWP. Figure 17 shows the spatial distribution of the annual mean indirect aerosol forcing when using the 1900 reference value over the study region. The European domain averaged annual mean radiative forcing is $-0.64 \mathrm{~W} \mathrm{~m}^{-2}$, with values reaching as high as $-1.3 \mathrm{~W} \mathrm{~m}^{-2}$. This is comparable to the estimate of $-0.96 \mathrm{~W} \mathrm{~m}^{-2}$ obtained by Carslaw et al. (2013) for the global mean forcing using the same reference period.

We also estimated the individual contribution of the first and second IAE to the total aerosol radiative forcing. This is done by turning off the individual IAEs by prescribing the fixed values for CDNCs as in the stand-alone RCA4 version in the radiation and cloud microphysics calculation (Lohmann and Feichter, 2001).

In IPCC-AR5 (Intergovernmental Panel for Climate Change - 5th Assessment Report) (Boucher et al., 2013) it 


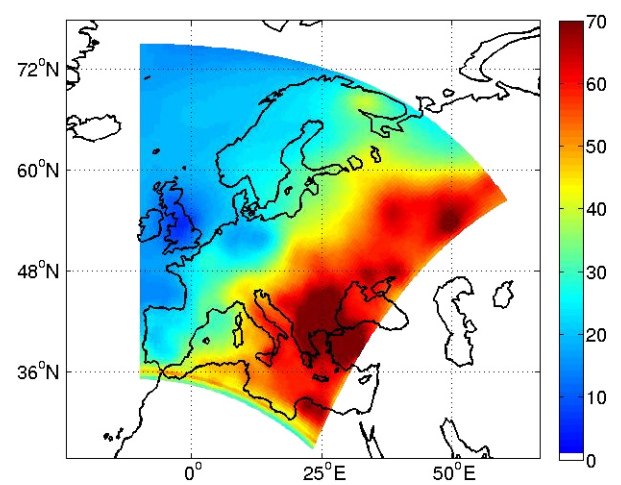

Figure 15. Difference in the annual mean CDNC for the (PD-PI) simulation expressed as a percentage.

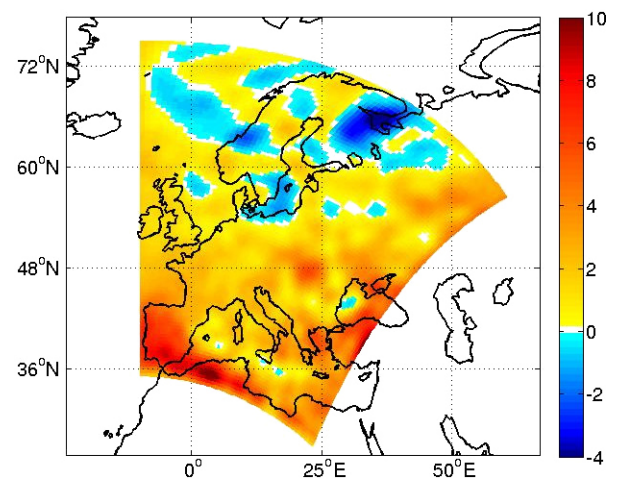

Figure 16. Difference in the annual mean CLWP for the (PD-PI) simulation expressed as a percentage.

was pointed out that the estimated values of the first IAE constitute the largest uncertainty and vary significantly between the different models. The impact of changes of aerosols on cloud albedo through the changes in droplet radius (first IAE) is estimated from our model setup to be $-0.57 \mathrm{~W} \mathrm{~m}^{-2}$ when averaged over the European domain. IPCC models estimated the global annual mean first IAE to be $-0.7 \mathrm{~W} \mathrm{~m}^{-2}$ and can vary widely from -1.8 to $-0.3 \mathrm{~W} \mathrm{~m}^{-2}$. However, the impact of changes of aerosols on cloud lifetime via the modification of precipitation efficiency is estimated to be $-0.14 \mathrm{~W} \mathrm{~m}^{-2}$ when averaged over the European domain used in this study. Studies have shown that the uncertainties in this are even larger compared to the first IAE. Depending on the autoconversion schemes used in the global models, Rotstayn and Liu (2005) showed that the global mean second IAE can vary from -0.71 to $-0.28 \mathrm{~W} \mathrm{~m}^{-2}$, of which the scheme used to obtain the value of $-0.28 \mathrm{~W} \mathrm{~m}^{-2}$ is more realistic.

\section{Conclusions}

In this study, we coupled the Rossby Center regional climate model (RCA4) for the offline ingestion of CDNCs from the cloud activation module that is embedded in the aerosol-

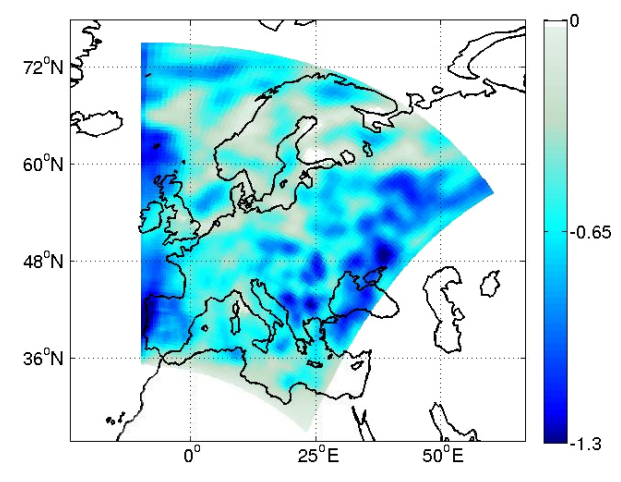

Figure 17. Annual mean aerosol radiative forcing at the TOA $\left(\mathrm{W} \mathrm{m}^{-2}\right)$.

chemistry transport model, MATCH-SALSA. Such a setup is beneficial mainly because a more sophisticated representation of aerosol distribution (emissions, transport and microphysical processes) can be included at a higher resolution compared to global models. Simulations were carried out with this setup for the period 2005-2012 over Europe using present-day emissions (PD) from EMEP for the year 2000 as well as using the stand-alone version of RCA4. We carried out two sets of analysis:

1. Investigate the improvements in a regional climate model simulation of the cloud microphysical properties, using spatially and temporally resolved 3-D CDNC fields from a detailed aerosol and cloud activation model.

2. Evaluate the indirect aerosol effects using this integrated modelling approach using the PI emissions taken from the ECLAIRE project. The particulate matter in the PI period are reduced to $14 \%$ of the current levels based on Carslaw et al. (2013).

This model setup improves the spatial, seasonal and vertical distribution of CDNCs with higher concentrations observed over central Europe during summer (JJA averaged) and over eastern Europe and Russia during winter (DJF averaged). Realistic cloud droplet radii numbers have been simulated with the maxima reaching $13 \mu \mathrm{m}$, whereas in the stand-alone version, the values reached only $5 \mu \mathrm{m}$. The standalone version of RCA4 overestimated the vertically integrated cloud water by up to $25 \%$ in winter and underestimated by a similar magnitude in summer over the European subcontinent. Comparisons with satellite retrievals from MODIS reveals a significant improvement in the LWP distribution; the median and standard deviation values obtained from the MOD simulation is much closer to observations than the CTRL simulation. A significant decrease by up to $-5 \mathrm{~W} \mathrm{~m}^{-2}$ in the total TOA net fluxes is simulated owing to these changes. The TOA net fluxes obtained with the new model setup show a better agreement with net flux retrievals from the CERES instrument than those computed with the 
old model setup. This confirms the importance of employing a realistic, dynamic description of aerosol number distribution fields in regional climate models.

Using the pre-industrial emissions from 1900s, we estimated an increase of around 50-70\% CDNCs over southern and eastern Europe and below $30 \%$ over the rest of Europe in the PD climate consistent with the increases in aerosol number concentrations, and correspondingly an increase in the CLWP is simulated over our study area. These changes resulted in an annual mean TOA radiative forcing over Europe of $-0.64 \mathrm{~W} \mathrm{~m}^{-2}$ which is comparable to previous estimates for the same reference period. It was also estimated that the contribution from the first $\operatorname{IAE}\left(-0.57 \mathrm{~W} \mathrm{~m}^{-2}\right)$ is larger than the contribution from the second IAE $\left(-0.14 \mathrm{~W} \mathrm{~m}^{-2}\right)$. This study shows a substantial improvement in the cloud microphysical properties and radiative fluxes with the offline coupled model setup. Hence, we recognize the need for an online coupled model system and we plan to implement SALSA directly into RCA4 in the future.

The calculations were performed on a HP Cluster Platform 3000 with SL230s Gen8 compute nodes, each with two 8-core Intel Xeon E5-2660 "Sandy Bridge" processors at 2.2 GHz. Using three nodes and 48 MPI-ranks, a 1-year simulation with the online coupled MATCH-SALSA including the cloud activation module takes $20 \mathrm{~h}$ (wall-clock time). On the other hand, RCA4 takes approximately $1.5 \mathrm{~h}$ for 1 -year simulation using two nodes and $32 \mathrm{MPI}-$ ranks. 


\section{Appendix A}

In a given time step $(t=n)$, the thermodynamic tendencies resulting from resolved dynamics and parameterized vertical turbulent fluxes are first calculated. These terms are stored in the relevant tendency terms $\left(\frac{\partial \chi}{\partial t}\right.$ at $\left.t=n\right)$. Next, the radiation scheme is called using the thermodynamic values (temperature, $T$; humidity, $q$; cloud water, cw) valid at $t=n$. After the radiation fluxes have been calculated, the model calls the surface scheme, followed by convection and, finally, condensation and cloud microphysics are called. On entering the microphysics scheme, the thermodynamic variables valid at $t=n$ are updated by the tendencies from dynamics and turbulence. For example,

$$
T=T_{n}+\Delta t \times\left\{\left.\frac{\partial T}{\partial t}\right|_{\text {dyn }}+\left.\frac{\partial T}{\partial t}\right|_{\text {turb }}\right\},
$$

and these variables are used to calculate a new value of $\mathrm{cw}$, $q$, etc., consistent with the updated saturated state of the at- mosphere. With this, calculated cloud water can increase locally due to the dynamical and turbulent terms, and this recalculated $\mathrm{CD}$ radii for the autoconversion process in the microphysics scheme may be substantially larger than in the radiation scheme (exceeding the threshold for precipitation onset of $10 \mu \mathrm{m}$ ). With the microphysics scheme, precipitation removal of generated cloud water is also parameterized; hence, the fraction of the newly generated cloud water is removed as rain. The resulting $\mathrm{cw}$ tendency due to condensation and subsequent precipitation removal is then incremented to $t=n$ values, along with all other tendencies from $t=n$ to give new values for the next time step. In this manner, $\mathrm{CD}$ radii in the microphysics scheme can increase above the threshold for onset of precipitation and then, as a result of this precipitation removal of cloud water, decrease again below the threshold. The low (precipitation affected) value of cloud water is what the radiation scheme "sees" in each time step leading to a low estimate in $\mathrm{CD}$ radii. 


\section{Code availability}

The different model source codes and the coupled system used in this study are not entirely available for open-source distribution at present, but can be made available to interested users/investigators upon request. The aerosol microphysics code SALSA is distributed under the Apache 2.0 license, while the regional climate model RCA4 and the chemistry transport model MATCH are available upon request from the SMHI.

Acknowledgements. This work was supported and funded by the Swedish Environmental Protection Agency through the CLEO (CLimate change and Environmental Objectives) and partly by the SCAC (Swedish Clean Air and Climate research program) projects. We also acknowledge the funding from FORMAS through MACCII (Modeling Aerosol-Cloud-Climate Interactions and Impacts) project. M. Kahnert acknowledges funding from the Swedish Research Council (Vetenskapsrådet) under project 621-2011-3346.

Edited by: A. Colette

\section{References}

Abdul-Razzak, H. and Ghan, S. J.: A parameterization of aerosol activation 3. Sectional representation, J. Geophys. Res., 107, AAC1.1-AAC1.6, doi:10.1029/2001JD000483, 2002.

Albrecht, B.: Aerosols, cloud microphysics, and fractional cloudiness, Science, 245, 1227-1230, 1989.

Andersson, C., Langner, J., and Bergström, R.: Interannual variation and trends in air pollution over Europe due to climate variability during 1958-2001 simulated with a regional CTM coupled to the ERA-40 reanalysis, Tellus, 59B, 77-98, 2007.

Andersson, C., Bergström, R., Bennet, C., Thomas, M., Robertson, L., Kokkola, H., Korhonen, H., and Lehtinen, K.: MATCH-SALSA: Multi-scale Atmospheric Transport and Chemistry model coupled to the SALSA aerosol microphysics model, SMHI RMK Report no 115, available at: http://www.smhi.se/publikationer/match-salsa-multi-scaleatmospheric-transport-and-chemistry-model-coupled-tothe-salsa-aerosol-microphysics-model-1.34623 (last access: 26 June 2015), 2013.

Andersson, C., Bergström, R., Bennet, C., Robertson, L., Thomas, M., Korhonen, H., Lehtinen, K. E. J., and Kokkola, H.: MATCHSALSA - Multi-scale Atmospheric Transport and CHemistry model coupled to the SALSA aerosol microphysics model Part 1: Model description and evaluation, Geosci. Model Dev., 8, 171-189, doi:10.5194/gmd-8-171-2015, 2015.

Baklanov, A., Korsholm, U., Mahura, A., Petersen, C., and Gross, A.: ENVIRO-HIRLAM: online coupled modelling of urban meteorology and air pollution, Adv. Sci. Res., 2, 41-46, 2008.

Baklanov, A., Schlünzen, K., Suppan, P., Baldasano, J., Brunner, D., Aksoyoglu, S., Carmichael, G., Douros, J., Flemming, J., Forkel, R., Galmarini, S., Gauss, M., Grell, G., Hirtl, M., Joffre, S., Jorba, O., Kaas, E., Kaasik, M., Kallos, G., Kong, X., Korsholm, U., Kurganskiy, A., Kushta, J., Lohmann, U., Mahura,
A., Manders-Groot, A., Maurizi, A., Moussiopoulos, N., Rao, S. T., Savage, N., Seigneur, C., Sokhi, R. S., Solazzo, E., Solomos, S., Sørensen, B., Tsegas, G., Vignati, E., Vogel, B., and Zhang, Y.: Online coupled regional meteorology chemistry models in Europe: current status and prospects, Atmos. Chem. Phys., 14, 317-398, doi:10.5194/acp-14-317-2014, 2014.

Barahona, D., Sotiropoulou, R., and Nenes, A.: Global distributionof cloud droplet number concentration, autoconversion rate, andaerosol indirect effect under diabatic droplet activation., J. Geophys. Res., 116, D09203, doi:10.1029/2010JD015274, 2011.

Boucher, O., Randall, D., Artaxo, P., Bretherton, C., Feingold, G., Forster, P., Kerminen, V.-M., Kondo, Y., Liao, H., Lohmann, U., Rasch, P., Satheesh, S. K., Sherwood, S., Stevens, B., and Zhang, X. Y.: Clouds and Aerosols, in: Climate Change 2013: The Physical Science Basis. Contribution of Working Group I to the Fifth Assessment Report of the Intergovernmental Panel on Climate Change, edited by: Stocker, T. F., Qin, D., Plattner, G.-K., Tignor, M., Allen, S. K., Boschug, J., Nauels, A., Xia, Y., Bex, V., and Midgley, P. M., Cambridge University Press, Cambridge, United Kingdom and New York, NY, USA, 2013.

Carslaw, K. S., Lee, L. A., Reddington, C. L., Pringle, K. J., Rap, A., Forster, P. M., Mann, G. W., Spracklen, D. V., Woodhouse, M. T., Regayre, L. A., and Pierce, J. R.: Large contribution of natural aerosols to uncertainty in indirect forcing, Nature, 503, 67-71, 2013.

Colarco, P., da Silva, A., Chin, M., and Diehl, T.: Online simulations of global aerosol distributions in the NASA GEOS-4 model and comparisons to satellite and ground-based aerosol optical depth, J. Geophys. Res.-Atmos., 115, D14207, doi:10.1029/2009JD012820, 2010.

Dusek, U., Frank, G. P., Hildebrandt, L., Curtius, J., Schneider, J., Walter, S., Chand, D., Drewnick, F., Hings, S., Jung, D., Borrmann, S., and Andreae, M. O.: Size matters more than chemistry for cloud nucleating ability of aerosol particles, Science, 213, 1375-1378, doi:10.1126/science.1125261, 2006.

Folberth, G. A., Rumbold, S., Collins, W. J., and Butler, T.: Regional and Global Climate Changes due to Megacities using Coupled and Uncoupled Models, D6.6, MEGAPOLI Scientific Report 11-07, MEGAPOLI-33-REP-2011-06, 18 pp., 2011.

Forster, P., Ramaswamy, V., Artaxo, P., Berntsen, T., Betts, R., Fahey, D., Haywood, J., Lean, J., Lowe, D., Myhre, G., Nganga, J., Prinn, R., Raga, G., Schulz, M., and Dorland, R. V.: Changes in Atmospheric Constituents and in Radiative Forcing, in: Climate Change: The Physical Science Basis. Contribution of Working Group I to the Fourth Assessment Report of the Intergovernmental Panel on Climate Change, edited by: Solomon, S., Qin, D., Manning, M., Chen, Z., Marquis, M., Averyt, K. B., Tignor, M., and Miller, H. L., Cambridge University Press, Cambridge, United Kingdom and New York, NY, USA, 2007.

Friedrich, R. and Reis, S. E.: Emissions of air pollutants - measurements, calculations and uncertainties, Springer, ISBN 9783-540-00840-8, 2004.

Grell, G. A., Peckham, S. E., Schmitz, R., McKenn, S. A., Frost, G., Skamarock, W. C., and Eder, B.: Fully coupled "online" chemistry within the WRF model, Atmos. Environ., 39, 6957-6975, 2005.

HTAP: Hemispheric Transport of Air Pollution 2010-Part A: Ozone and Particulate Matter, edited by: Dentener, F., Keating, T., and 
Akimoto, H., United Nations, New York and Geneva, Air Pollution Studies, 17, 135-198, 2010.

Hubanks, P. A., King, M. D., Platnick, S., and Pincus, R.: MODIS Atmosphere L3 Gridded Product Algorithm Theoretical Basis Document - Collection 5, Version 1.1., 1-96, 2008.

Huszar, P., Miksovsky, J., Pisoft, P., Belda, M., and Halenka, T.: Interactive coupling of a regional climate model and a chemical transport model: evaluation and preliminary results on ozone and aerosol feedback, Clim. Res., 51, 59-88, 2012.

Kokkola, H., Korhonen, H., Lehtinen, K. E. J., Makkonen, R., Asmi, A., Järvenoja, S., Anttila, T., Partanen, A.-I., Kulmala, M., Järvinen, H., Laaksonen, A., and Kerminen, V.-M.: SALSA - a Sectional Aerosol module for Large Scale Applications, Atmos. Chem. Phys., 8, 2469-2483, doi:10.5194/acp-8-2469-2008, 2008.

Kuenen, J., Denier van der Gon, H., Visschedijk, A., van der Brugh, H., and van Gijlswijk, R.: MACC European emission inventory for the years 2003-2007, TNO report, TNO-060-UT-201100588, 2011.

Lohmann, U. and Feichter, J.: Can the direct and semi-direct aerosol effect compete with the indirect effect on a global scale?, Geophys. Res. Lett., 28, 159-161, 2001.

Lohmann, U. and Feichter, J.: Global indirect aerosol effects: a review, Atmos. Chem. Phys., 5, 715-737, doi:10.5194/acp-5-7152005, 2005.

Lohmann, U., Feichter, J., Chuang, C. C., and Penner, J. E.: Prediction of the number of cloud droplets in the ECHAM GCM, J. Geophys. Res., 104, 9169-9198, 1999.

Mårtensson, E. M., Nilsson, E. D., de Leeuw, G., Cohen, L. H., and Hansson, H.-C.: Laboratory simulations and parametrization of the primary marine aerosol production, J. Geophys. Res., 108, 4297, doi:10.1029/2002JD002263, 2003.

McFiggans, G., Artaxo, P., Baltensperger, U., Coe, H., Facchini, M. C., Feingold, G., Fuzzi, S., Gysel, M., Laaksonen, A., Lohmann, U., Mentel, T. F., Murphy, D. M., O’Dowd, C. D., Snider, J. R., and Weingartner, E.: The effect of physical and chemical aerosol properties on warm cloud droplet activation, Atmos. Chem. Phys., 6, 2593-2649, doi:10.5194/acp-6-2593-2006, 2006.

Monahan, E. C., Spiel, D. E., and Davidson, K. L.: A model of marine aerosol generation via whitecaps and wave disruption, in: Oceanic Whitecaps and Their Role in Air-Sea Exchange 688, edited by: Monahan, E. C. and Mac Niocaill, G., D Reidel, Norwell, MA, 167-174, 1986.

Moore, R. H., Karydis, V. A., Capps, S. L., Lathem, T. L., and Nenes, A.: Droplet number uncertainties associated with CCN: an assessment using observations and a global model adjoint, Atmos. Chem. Phys., 13, 4235-4251, doi:10.5194/acp-13-42352013, 2013.

O’Dowd, C. D., Facchini, M. C., Cavalli, F., Ceburnis, D., Mircea, M., Decesari, S., Fuzzi, S., Yoon, Y. J., and Putaud, J.-P.: Biogenically driven organic contribution to marine aerosol, Nature, 431, 676-680, 2004.

Penner, J. E., Dong, X., and Chen, Y.: Observational evidence of a change in radiative forcing due to the indirect aerosol effect, Nature, 427, 231-234, 2004.

Platnick, S., King, M. D., Ackerman, S. A., Menzel, W. P., Baum, B. A., Riedi, J. C., and Frey, R. A.: The MODIS cloud products: Algorithms and examples from Terra., IEEE T. Geosci. Remote Sens., 41, 459-473, doi:10.1109/TGRS.2002.808301, 2003.
Pouliot, G., Pierce, T., Denier van der Gon, H., Schaap, M., Moran, M., and Nopmongcol, U.: Comparing emission inventories and model-ready emission datasets between Europe and North America for the AQMEII project, Atmos. Environ., 53, 4-14, 2012.

Qian, Y. and Giorgi, F.: Interactive coupling of regional climate and sulfate aerosol models over east Asia, J. Geophys. Res., 104, 6477-6499, 1999.

Qian, Y., Giorgi, F., and Huang, Y.: Regional simulation of anthropogenic sulfur over East Asia and its sensitivity to model parameters, Tellus, 53B, 171-191, 2001.

Robertson, L., Langner, J., and Engardt, M.: An Eulerian LimitedArea Atmospheric Transport model, J. Appl. Meteorol., 38, 190210, 1999.

Rotstayn, L. D. and Liu, Y.: A smaller global estimate of the second indirect aerosol effect, Geophys. Res. Lett., 32, L05708, doi:10.1029/2004GL021922, 2005.

Samuelsson, P., Jones, C., Willen, U., Ullerstig, A., Gollvik, S., Hansson, U., Jansson, C., Kjellström, E., Nikulin, G., and Wyser, K.: The Rossby Center Regional Climate model RCA3: model description and performance, Tellus A, 63, 4-23, 2011.

Simpson, D., Guenther, A., Hewit, C., and Steinbrecher, R.: Biogenic emissions in Europe. 1. Estimates and uncertainties, J. Geophys. Res., 100, 22875-22800, 1995.

Spracklen, D. V., Carslaw, K. S., Merikanto, J., Mann, G. W., Reddington, C. L., Pickering, S., Ogren, J. A., Andrews, E., Baltensperger, U., Weingartner, E., Boy, M., Kulmala, M., Laakso, L., Lihavainen, H., Kivekäs, N., Komppula, M., Mihalopoulos, N., Kouvarakis, G., Jennings, S. G., O’Dowd, C., Birmili, W., Wiedensohler, A., Weller, R., Gras, J., Laj, P., Sellegri, K., Bonn, B., Krejci, R., Laaksonen, A., Hamed, A., Minikin, A., Harrison, R. M., Talbot, R., and Sun, J.: Explaining global surface aerosol number concentrations in terms of primary emissions and particle formation, Atmos. Chem. Phys., 10, 4775-4793, doi:10.5194/acp-10-4775-2010, 2010.

Storelvmo, T., Lohmann, U., and Bennartz, R.: What governs the spread in shortwave forcings in the transient IPCC AR4 models?, Geophys. Res. Lett., 36, L01806, doi:10.1029/2008GL036069, 2009.

Twomey, S.: The nuclei of natural cloud formation part II: the supersaturation in natural clouds and the variation of cloud droplet concentration, Pure Appl. Geophys., 43, 243-249, 1959.

Visschedijk, A. J. H., Denier van der Gon, H., Dröge, A. C., Van der Brugh, H., and Kooter, I. M.: A European high resolution and size-differentiated emission inventory for elemental and organic carbon for the year 2005, TNO report, TNO-034UT-2009-00688-RPT-ML, 2009.

Wielicki, B. A., Cess, R. D., King, M. D., Randall, D. A., and Harrison, E. F.: Mission to Planet Earth: Role of Clouds and Radiation in Climate, B. Am. Meteorol. Soc., 77, 853-868, 1996.

Wyser, K., Rontu, L., and Savijärvi, H.: Introducing the Effective Radius into a Fast Radiation Scheme of a Mesoscale Model, Contr. Atmos. Phys., 72, 205-218, 1999.

Yttri, K. E., Dye, C., Braathen, O.-A., Simpson, D., and Steinnes, E.: Carbonaceous aerosols in Norwegian urban areas, Atmos. Chem. Phys., 9, 2007-2020, doi:10.5194/acp-9-2007-2009, 2009.

Yttri, K. E., Lund Myhre, C., Eckhardt, S., Fiebig, M., Dye, C., Hirdman, D., Ström, J., Klimont, Z., and Stohl, A.: Quantifying black carbon from biomass burning by means of levoglu- 
cosan - a one-year time series at the Arctic observatory Zeppelin, Atmos. Chem. Phys., 14, 6427-6442, doi:10.5194/acp-14-64272014, 2014.

Yu, F. and Luo, G.: Simulation of particle size distribution with a global aerosol model: contribution of nucleation to aerosol and CCN number concentrations, Atmos. Chem. Phys., 9, 76917710, doi:10.5194/acp-9-7691-2009, 2009.
Zeng, S., Riedi, J., Trepte, C. R., Winker, D. M., and Hu, Y.-X.: Study of global cloud droplet number concentration with A-Train satellites, Atmos. Chem. Phys., 14, 7125-7134, doi:10.5194/acp14-7125-2014, 2014. 